American Journal of Economics and Business Administration 2 (3): 323-329, 2010

ISSN 1945-5488

(C) 2010 Science Publications

\title{
Trends in Preferences in the Market for Alternative Investments: A Summary of Recent Deutsche Bank Alternative Investment Surveys
}

\author{
Erik Benrud \\ 101 North 33rd Street, Lebow College of Business, \\ Drexel University, Philadelphia, PA 19104
}

\begin{abstract}
Problem statement: This study introduced to the literature information on and from the Deutsche Bank Alternative Investment Survey: 2002-2009. Approach: All the survey data for our analysis is from the DBAIS survey. We obtained the interest rate data, from the St. Louis Federal Reserve. Results: Our results present important summaries of the trends and relationships among participants in the alternative investments market. The importance of the survey is evident by the growth from 168 to over 1000 respondents and the number of questions has tripled. Conclusion/Recommendations: Interesting findings include a dramatic increase in the use of managed accounts. Also, planned increases in allocations to the styles distressed debt and convertible arbitrage are positively correlated with each other and the Baa bond rate and they are each negatively correlated with planned increases in allocations to most other styles.
\end{abstract}

Key words: Alternative investments, hedge funds, Deutsche Bank

\section{INTRODUCTION}

The Deutsche Bank Alternative Investment Survey (DBAIS) provides the opinions, forecasts and summaries of activities of hundreds of participants in the market for alternative investments. Our analysis of the survey to date accomplishes two important goals. First, although relatively short, the data is sufficient to provide descriptive measures of interesting trends during the period and interesting relationships among planned additions to different styles. Second, we call attention to the DBAIS. More practitioners and researchers can benefit if they are aware of it and those who conduct the DBAIS can get feedback on ways to improve the survey and make the survey more useful in the future.

Our study is part of ongoing research into the properties of financial and economic surveys. Such literature routinely includes summaries of the results up to a certain point of time, e.g., "History of the Forecasters: An Assessment of the Semi-Annual US Treasury Bond Yield Forecast Survey as Reported in The Wall Street Journal" by Brooks and Gray (2004).

Surveys take time to develop both in terms of length of the series and also with respect to the questions the survey asks. The popular Wall Street Journal semiannual survey (WSJ survey) is an example of how a survey evolved over time. For one thing, it did not start out semiannual. The results of the first WSJ survey appeared in July, 1982 and provided the forecasts of only fourteen economists for the prime rate, the three-month Treasury bill rate and the thirty-year Treasury bond rate. The next survey appeared a year later. It provided the forecasts of only 17 economists for only the Treasury bill rate and the thirty-year Treasury bond rate; however, it began the practice of providing forecasts for both six-month and twelve month horizons and subsequent surveys appeared every six months. In 1986, the survey began to include forecasts for GDP, inflation and unemployment in addition to the interest rate data. In 1989, the survey added forecasts of exchange rates and there were 39 contributing forecasters. The most recent WSJ survey had 51 contributors.

\section{MATERIALS AND METHODS}

All the survey data for our analysis is from the DBAIS survey. We obtained the interest rate data, from the St. Louis Federal Reserve. We provide descriptive charts, linear correlations and the results from OLS regressions.

We analyze the data from the seven surveys in cases where there are at least four time-series observations available. The topics of analysis are dollar allocations to alternative investments, the size of funds in which the participants invest, the use of managed accounts, lockup preference, liquidity preference and allocations to six investment styles. We provide some trend analysis as well as correlation and regression results that can provide insights into how hedge fund managers make choices among various styles. The importance of the survey is reflected in the growth of the number of questions. 
Am. J. of Economics and Business Administration 2 (3): 323-329, 2010

Table 1: Reported number of respondents

\begin{tabular}{|c|c|c|}
\hline Survey & Number & Description \\
\hline 2002 & 168 & $\begin{array}{l}\text { "168 institutional investors who were either investing or were considering investing in } \\
\text { alternative assets" (p. 4) }\end{array}$ \\
\hline 2003 & 376 & "376 alternative asset investors". (p. 4) \\
\hline 2004 & 323 & "323 hedge fund investors". (p. 4) \\
\hline 2005 & $\begin{array}{l}\text { "Over 1,000 representatives" } \\
\text { and " } 650 \text { firms" }\end{array}$ & $\begin{array}{l}\text { "Over 1,000 representatives from } 650 \text { firms. These } 650 \text { investors represent } \$ 645 \text { billion } \\
\text { "Nearly two-thirds of all assets in the hedge fund industry." (p. 2) }\end{array}$ \\
\hline $2006 / 2007$ & $\begin{array}{l}\text { "More than a thousand investors" } \\
\text { " and "almost seven hundred firms }\end{array}$ & $\begin{array}{l}\text { "More than a thousand investors from almost seven hundred firms" } \\
\text { "Almost two-thirds of the hedge fund industry". (p. 2) }\end{array}$ \\
\hline 2008 & $\begin{array}{l}\text { "More than } 1000 \text { respondents } \\
\text { from over } 500 \text { firms" }\end{array}$ & $\begin{array}{l}\text { "More than } 1000 \text { respondents from over } 500 \text { firms, presenting nearly } \$ 1 \text { trillion in hedge } \\
\text { funds assets and more than } \$ 4.5 \text { trillion in total portfolio assets". }\end{array}$ \\
\hline 2009 & $1,000 \mathrm{~s}$ & "1,000 investors. They collectively manage more than $\$ 1.1$ trillion in hedge fund assets". \\
\hline
\end{tabular}

Table 2: Questions asked in the March 2002 survey

Alternative investment survey participants.

Types of alternative investment made by the survey group. Percentage of all surveyed participants who used consultants. Percentage of participants who invest in either Hedge Fund or funds of funds, or both.

Direct investments into hedge funds.

Typical size of direct investments.

Asset size requirements.

Typical number of annual direct investment allocations.

Most frequent number of allocations per year.

Average length of time hedge fund investments.

are held before redemption

Investor profile at early stages in the life of a Hedge fund (start-up investments)

Investor profile at early stages in the life of a Hedge fund (1 year record)

Distribution of investors requiring longer manager track records (2 year record)

Table 2 lists the questions in the first survey in 2002 and Table 3 provides the much larger list of questions from the most recent survey. The results from such a long list can provide the motivation and data for future research. For example, the more recent surveys ask for forecasts of the returns of the S\& P 500 and the MSCI and future research can test the accuracy of the responses.

Among the more interesting observations we make in our study are the strong increase in the use of managed accounts and the steady increase in early years and recent decline in the size of intended allocations. Based upon the data concerning the proportion of investors who intended to add to their allocations to the different investment-style classes in each year, it appears that conditions that make investors increase allocations to distressed debt also make them increase allocations to convertible arbitrage. The percent of respondents who intend to add to allocations to these fixed income classes is generally negatively correlated with the corresponding percent for the other four classes: long/short strategy, global macro, multi-strategy and statistical arbitrage. Furthermore, a higher Baa interest rate seems to
Distribution of investors requiring longer manager track records (3 year record).

Selection standards that investors look for.

How investors discover hedge funds.

Frequency of reviewing hedge fund managers.

What investors want a hedge fund to disclose.

Capacity limits for investments.

Early stage investors; special concessions required for investment.

Structured equity finance in portfolio.

Investments into Funds of Funds.

Percentage who invest in fund of funds.

Typical fund of funds investment size

Length of holding period for fund of funds investments

Hurdles to investing in funds of funds increase the percent that will add to allocations to the distressed debt and convertible arbitrage styles and reduce that percent in the case of the other styles.

\section{RESULTS AND DISCUSSION}

The data and summary observations: The DBAIS results were published in March 2002, January 2003, February 2004, July 2005, winter 2006/2007, May 2008 and March 2009. The number of respondents has grown by a factor of six from the first survey: from 168 to 1000 or more. Table 1 provides the number for each year and indicates how the DBAIS described the participants in each survey. The number of questions has grown, too. The first survey provided summary measures for the responses from less than 30 questions. Table 2 provides the list of questions from the March 2002 survey. The number of questions grew to about 50 by the 2004 survey and remained around that number for the following three surveys. The March 2009 survey had 90 questions. As Table 3 indicates, some of the original questions from the March 2002 survey have been removed or revised. 
Table 3: Questions asked in the March 2009 survey Investor categories: Survey respondents 2009.

Do you directly invest in HFs, Fund of Funds or Private Equity?

Type of organization.

How would you describe your firm

(Europe, America, or Asia)?

Main benefits of Hedge Fund investments.

Expected Hedge Fund inflows in 2009.

Applied portfolio leverage.

How leverage changed over the last 12 months.

The average size of the Hedge Funds invested in.

The average size of the Hedge Funds

invested in.

Five most important factors when assessing a

Hedge Fund manager.

Five most important factors when assessing a Hedge Fund manager (2008 Vs 2009).

Usage of managed accounts.

Hedge Fund strategies predicted to perform best in 2009 .

Percentage of respondents planning to increase allocations by strategy.

Regions predicted to perform best in 2009.

Regions predicted to perform worst in 2009.

The biggest challenges your managers face over the next

12 months.

Hedge Fund strategy performance 2008 through December.

HFRI composite less MSCI world \% return (1998-2008).

Hedge Fund performance vs. Leading indices (2008).

Forecasting S\&P 500 returns for 2009.

Forecasting MSCI World returns for 2009.

Forecasting MSCI emerging markets returns for 2009

Forecasting HFR Hedge Fund Index returns for 2009.

Forecasting your own Hedge Fund

investments returns for 2009.

Percentage of respondents planning.

to reduce allocations by strategy.

Hedge Fund strategies predicted to perform worst in 2009.

Allocation plans among 19 classes (Equity long/short,

Equity relative value, event driven, market neutral.

Intention to add to, reduce or maintain your allocations

to eastern and Central Europe (ex-Russia)

Intention to add to, reduce, or maintain your allocations

to Russia.

Intention to add to, reduce, or maintain your allocations to the US/Canada.

Intention to add to, reduce, or maintain your allocations to

Western Europe.

Intention to add to, reduce, or maintain your allocations

to China.

Intention to add to, reduce, or maintain your allocations

to Japan.

Intention to add to, reduce, or maintain your allocations

to India.

Intention to add to, reduce, or maintain your allocations

to Asia (ex-Japan).

Intention to add to, reduce, or maintain your allocations

to Latin America.

Intention to add to, reduce, or maintain your allocations to

the middle East and North Africa.

Intention to add to, reduce, or maintain your allocations

to $\mathrm{S}$. Africa.

Do you make direct investments in 130/30 strategies (by

region and by investor type)?

UTITS III (by region and by investor type).

Have you participated in the secondary market for Hedge Fund stakes in 2008 ?

Do you expect to participate in the secondary

market for hedge fund stakes in 2009?

Categorize prospective secondary market participates by firm type.
Following the events of 2008 , will you be more likely to make a proportion of your investments through managed accts in the future? Usage of managed accounts.

The most attractive features of managed accounts.

If you use managed accounts, which of the following routes would you be likely to use?

What kind of portfolio info. will you require from HF managers?

Size of Hedge Fund investment (by respondents and over years).

Number of years your firm has been investing in Hedge Fund

Number of managers you invest with directly (2005-2009).

Average Hedge Fund allocations since 2002.

Size of initial allocations to Hedge Funds last year.

Size of follow-on allocations to Hedge Funds last year.

Does your mandate limit your Hedge Fund allocation to a certain percentage?

Do you make direct investments in Hedge Fund replicators?

Do you invest day one?

Biggest challenges you face when it comes to investing.

Average time to process due diligence.

Frequency of portfolio rebalance.

Number of full redemptions made in the last 12 months.

Number of partial redemptions made in the last 12 months.

Percentage of cash currently held in your portfolio.

What will be your cash positions in 6 months?

Do your seed managers get discounted fees, participation in economics, or equity stakes?

Do you require a fee for seeding?

Do you use consultants?

Percentage of respondents using consultants (2002-2009).

Consultant clients by region.

Consultants: client breakdown.

Average consultant: Client base.

The longest lock up that you will accept on new Hedge Fund investments.

Maximum lock up you are willing to accept (2009).

Maximum lock up you are willing to accept (2008).

The longest lock up that you will accept on new Hedge Fund investments by region.

Willingness of accepting longer lock-ups in exchange for lower management fees.

Would you consider a Hedge Fund with a private equity-style structure for less liquid assets.

What liquidity do you require, even in the case of a lock-up?

The maximum notice period acceptable by investor type.

Willingness of considering investing in a Hedge Fund with a side-pocket.

Do you require a minimum AUM before investing (2009)?

Do you require a minimum fund AUM before investing (2002)?

Percentage of hedge fund managers will go out of business in 2009.

Do you require hedge fund to have a track record before you invest?

Willingness of considering investing in a Fund which experienced a maximum drawdown of various amounts.

Willingness of considering investing in a Fund which has experienced certain outcomes.

Rank in order which of the following is perceived as most damaging to a

funds' reputation.

View with respect to in-kind destructions from Hedge Funds (i.e., receiving securities upon submission of a redemption notice) 
Am. J. of Economics and Business Administration 2 (3): 323-329, 2010

Table 4: Distribution of participants each survey

\begin{tabular}{lrrrrrrrr}
\hline & 2002 & 2003 & 2004 & 2005 & $2006 / 2007$ & 2008 & 2009 & Trend Corr. \\
\hline Bank & 4 & 7 & 7 & 9 & 6 & 7 & 9 & 0.6236 \\
Insurance company & 4 & 3 & 3 & 3 & 3 & 1 & 4 & -0.3086 \\
Fund of funds & 35 & 50 & 55 & 43 & 47 & 40 & 51 & 0.2224 \\
Family office & 13 & 16 & 14 & 15 & 12 & 17 & 13 & 0.0000 \\
Pension & 20 & 5 & 5 & 11 & 9 & 8 & 5 & -0.5014 \\
Endowment/foundation & 13 & 10 & 6 & 7 & 7 & 7 & 3 & -0.8559 \\
Other & 6 & 4 & 5 & 6 & 6 & 5 & 7 & 0.4743 \\
Consultant & 5 & 3 & 3 & 2 & 6 & 13 & 7 & 0.5990 \\
Hedge funds & - & 2 & 2 & - & - & - & - & 1 \\
Corporations & - & - & - & 4 & 4 & 2 & & \\
\hline
\end{tabular}

Note: Figures are percents for each survey. The last column is the correlation of each row with a time trend

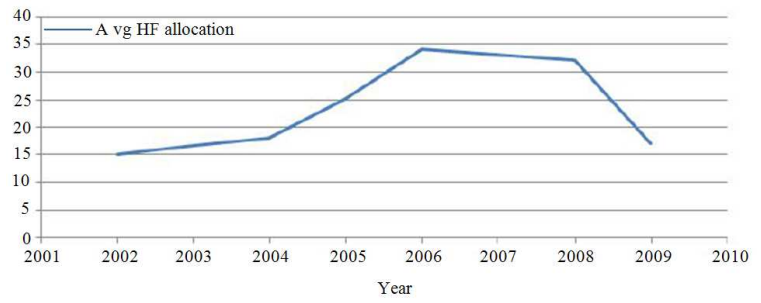

Fig. 1: Average dollar allocation to hedge funds (\$millions)

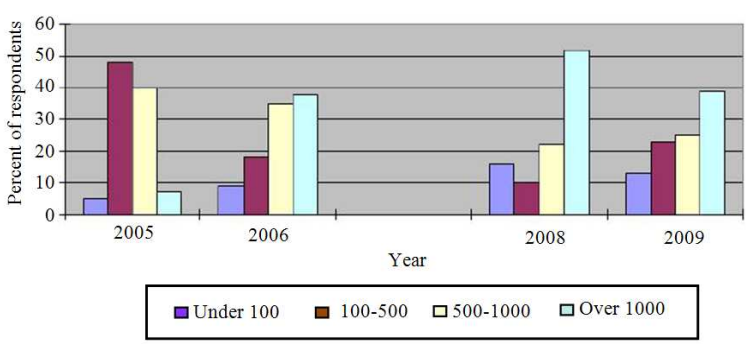

Fig. 2: Percent invested in indicated size of fund: Under $100 \mathrm{~m} \$, 100-500 \mathrm{~m} \$, 500 \mathrm{~m} \$-\$ 1 \mathrm{~b}$, over $\$ 1 \mathrm{~b}$ (no data available for 2006/2007)

Table 4 provides the breakdowns of how the respondents characterized themselves by type of institution. The last column of Table 4 is a simple correlation coefficient of the time series of each proportion with a linear trend variable. It gives an indication of the degree to which the proportion increased or decreased over time. There was a strong relative increase in the participation of banks in the survey and a strong relative decrease in participation from endowments and foundations. Each year, the largest group of respondents classified themselves as fund of funds. The range of the proportions for this class was $35-55 \%$, with a slight positive trend over the years.

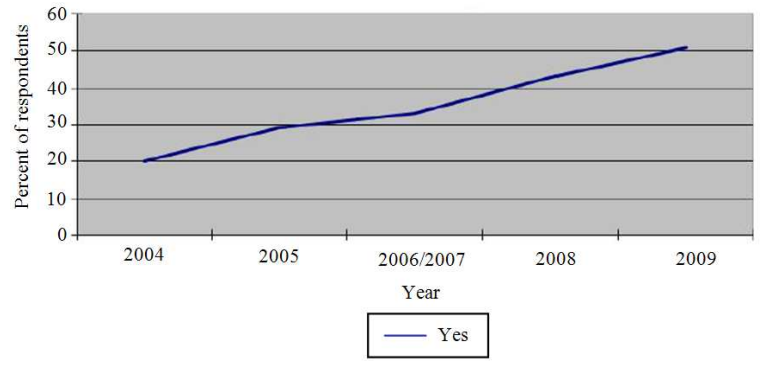

Fig. 3: Percent of investors that use managed account

As Fig. 1 indicates, the expected investments or "ticket size" grew in the early years of the time period and began to decline in the last two years. This is not surprising given the downturn in the financial industry starting in 2007. Published reports in the media validate that there has been a net outflow of capital from the hedge fund market in 2008 and 2009, Kouwe (2009) and Kishan (2009). Figure 2 illustrates the recent decline in the size of funds in which investors made allocations. In 2008, over half of the respondents indicated that they would be investing in a fund that had assets under management in excess of $\$ 1$ billion. In 2009 , less than $40 \%$ gave that response. Perhaps the economic environment also explains the steady increase in the use of managed accounts as illustrated in Fig. 3. The $\mathrm{t}$-statistic for a regression of the preferences on a trend variable is 15.51, which is significant using Chebyshev's Theorem.

Figure 4 and 5 describe the preferences for liquidity levels and lockup periods. The preference for liquidity is measured by the frequency of redemptions where "monthly" is the highest level of liquidity. It is interesting to note that there is not a clear trend in either case. With increases in risk aversion from the increase in uncertainty in 2008 and 2009 , we might expect that investors would prefer both increased liquidity and shorter lockup periods. However, there have been changes in the market and industry such as the fee structures charged by funds. 
The 2009 DBAIS survey reports that investors are receptive to longer lockups for lower fees and many funds are offering the choice of lower fees with a longer lockup, $\mathrm{Hu}$ (2008). With respect to liquidity, Phillips (2009) notes that over the years 2002-2007 when capital was flowing into the hedge fund market, hedge funds had gone from quarterly to monthly liquidity. As capital has been flowing out in more recent years, there is the beginning of a trend back to quarterly subscriptions and redemptions. Additional reasons for a higher tolerance for lockups and lower liquidity may be found in Agarwal et al. (2009) who report that managers who have more discretion as measured by longer lockups and less-frequent redemptions deliver higher returns. The main point is that the increase in the percentages for the longer periods on Fig. 4 and 5 may be the result of changing expectations for what is the optimal lockup and liquidity level given other market conditions.

Changing market conditions will influence investors' planned allocations among the various styles. Beginning with the 2003 survey, the DBAIS asked the respondents their "Allocation Plans" for a list of alternative investment styles. The respondents could respond with "Add", "Maintain", or "Reduce". For our analysis, we focus on the proportion for "Add" in each case. Table 5 lists the percentage of investors who reported they planned to "Add" to their allocations to the indicated styles. For brevity, we will refer to this variable as the allocation-plansadd variable or APA. The last column on Table 5 has a time-trend correlation for each APA series. There was a strong positive trend in plans to add allocations to distressed debt over the sample period. The APA with the strongest negative trend is the long/short strategy.
Analysis of allocation plans across styles: The analysis of correlations of the percent of investors who plan to increase allocations to the various styles, or APAs, gives insights into how investors move among styles. When more investors are increasing their allocations to one style, which other style tends to have fewer investors adding allocations to it? Our analysis also explores how investors might see certain styles as having similar risk factor exposures. For this initial study, we measure the correlations between the various APAs and we measure the correlation of each APA with interest-rate measures and perform some regressions.

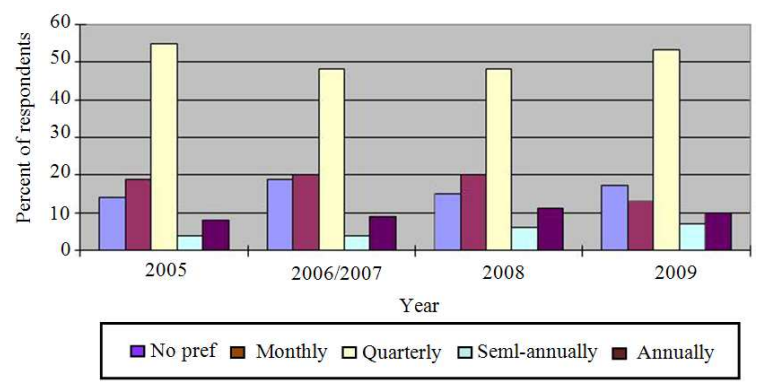

Fig. 4: Level of liquidity required

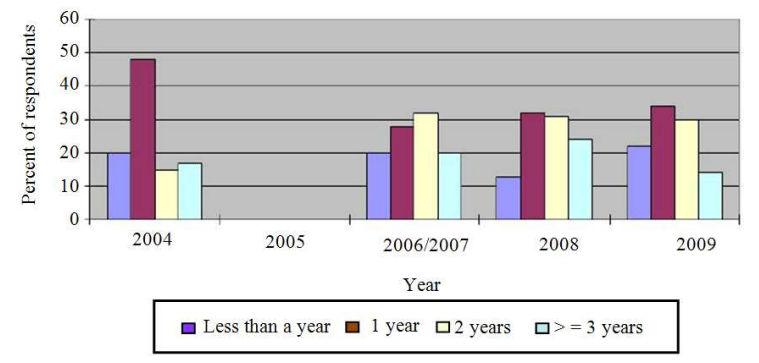

Fig. 5: Maximum acceptable lockup period (no data for 2005)

Table 5: The APAs: The percent of respondents who indicated they would "add" to their allocations to the indicated style. The last column is the correlation of each row with a time trend

\begin{tabular}{|c|c|c|c|c|c|c|c|}
\hline & 2003 & 2004 & 2005 & $2006 / 2007$ & 2008 & 2009 & Trend Corr. \\
\hline Long/short equity & 52 & 54 & 58 & 36 & 30 & 31 & -0.8476 \\
\hline Conv. arbitrage & 26 & 20 & 16 & 28 & 25 & 22 & 0.0850 \\
\hline Distressed (debt) & 44 & 15 & 18 & 33 & 60 & 41 & 0.4260 \\
\hline Global macro & 48 & 40 & 59 & 32 & 21 & 47 & -0.3564 \\
\hline Stat. arbitrage & 32 & 21 & 23 & 24 & 26 & 13 & -0.6765 \\
\hline Multi-strategy & 45 & 30 & 40 & 26 & 31 & 11 & -0.8168 \\
\hline
\end{tabular}

Table 6: Correlation between planned allocation additions to indicated styles (APAs)

\begin{tabular}{llcccrr}
\hline & Statistic & Conv. arbitrage & Distressed debt & Long/short & Global macro & Multi strategy \\
\hline Distressed debt & Corr. coef. (p-value) & $0.644(0.167)$ & & & & \\
Long/short & Corr. coef. (p-value) & $-0.578(0.23)$ & $-0.731(0.099)$ & & & \\
Global macro & Corr. coef. (p-value) & $-0.657(0.157)$ & $-0.592(0.216)$ & $0.684(0.134)$ & & \\
Multi-strategy & Corr. coef. (p-value) & $-0.090(0.865)$ & $-0.116(0.827)$ & $0.708(0.115)$ & $0.236(0.653)$ & \\
Statistical arbitrage & Corr. coef. (p-value) & $0.394(0.439)$ & $0.253(0.628)$ & $0.338(0.512)$ & $-0.154(0.771)$ & $0.875(0.022)$ \\
\hline
\end{tabular}


Am. J. of Economics and Business Administration 2 (3): 323-329, 2010

Table 7: Correlations of APAs with interest-rate measures

\begin{tabular}{llrrrr} 
& Statistic & \multicolumn{1}{c}{ T-Bond } & \multicolumn{1}{c}{ Aaa } & \multicolumn{1}{c}{ Baa } & \multicolumn{1}{c}{ Baa/Aaa } \\
\hline Convertible arbitrage & Corr. coef. (p-value) & $0.107(0.840)$ & $0.562(0.245)$ & $0.319(0.538)$ & $-0.027(0.960)$ \\
Distressed debt & Corr. coef. (p-value) & $-0.361(0.481)$ & $0.423(0.404)$ & $0.600(0.208)$ & $0.370(0.470)$ \\
Long/short strategy & Corr. coef. (p-value) & $0.200(0.705)$ & $0.083(0.876)$ & $-0.497(0.316)$ & $-0.598(0.210)$ \\
Global macro & Corr. coef. (p-value) & $-0.007(0.989)$ & $-0.197(0.708)$ & $-0.046(0.931)$ & $0.085(0.873)$ \\
Multistrategy & Corr. coef. (p-value) & $0.288(0.580)$ & $0.421(0.406)$ & $-0.440(0.383)$ & $-0.769(0.074)$ \\
Statistical arbitrage & Corr. coef. (p-value) & $0.283(0.587)$ & $0.657(0.157)$ & $-0.245(0.640)$ & $-0.713(0.112)$ \\
\hline
\end{tabular}

Table 8: Regression of APAs on the treasury bond rate and the Baa rate

\begin{tabular}{lccclll}
\hline & Convertible arbitrage & Distressed debt & Long/short strategy & Global macro & Multi-strategy & Statistical arbitrage \\
\hline Intercept (t-stat.) & $31.800(-1.00)$ & $-106.000(-0.800)$ & $163.600(1.620)$ & $62.20(0.460)$ & $95.700(0.890)$ & $21.880(0.360)$ \\
T-Bond coef. (t-stat.) & $4.056(1.54)$ & $5.390(0.490)$ & $-6.466(-0.770)$ & $-1.500(-0.130)$ & $-2.0870(-0.230)$ & $1.310(0.260)$ \\
Baa coef. (t-stat.) & $6.374(1.71)$ & $18.490(1.18)$ & $-14.990(-1.260)$ & $-2.480(-0.160)$ & $-8.700(-0.690)$ & $-0.3350(-0.05)$ \\
Adj. R-sqd. & $16.40 \%$ & $1.200 \%$ & $0.000 \%$ & $0.000 \%$ & $0.000 \%$ & $0.000 \%$ \\
F-statistic & 1.490 & 1.0300 & 0.8800 & 0.0100 & 0.3900 & 0.130 \\
\hline
\end{tabular}

The chosen interest rate measures are the three-year Treasury bond rate, the Aaa bond rate, the Baa bond rate and the ratio of the Baa bond rate to the Aaa bond The data is from the St. Louis Federal Reserve: http://www.federalreserve.gov/releases/h15/data.htm. We chose the three-year Treasury rate because that corresponds to an intermediate investment horizon.

For the styles themselves, the strongest positive correlation is between the APAs of the multi-strategy and statistical arbitrage styles. The correlations are in Table 6. The strongest negative correlation is between the APAs of the long/short strategy and distressed debt styles. There are positive correlations among the APAs of the styles distressed debt, convertible arbitrage and statistical arbitrage. All of the correlations are positive among the APAs of the styles long/short strategy, global macro and multi-strategy. The correlations between any one of the first group and any one of the second group are negative in almost all cases.

Given that there are only six observations, we do not offer any conclusions. Based on the evidence we do provide, however, it seems that the convertible arbitrage and distressed debt styles have properties that make them distinct from the other classes. Those properties include the positive correlation of their APAs and their sensitivities to certain interest rate measures. We measure the sensitivities of the APAs to a fairly standard group of interest rates: the three-year Treasury bond rate, the Aaa bond rate and the Baa bond rate. We also include the ratio of the Aaa bond rate to the Baa bond rate as a risk-premium measure.

The correlations of each APA with each interestrate measure are on Table 7. The one pattern on Table 7 worthy of note is that the APAs of the styles distressed debt and convertible arbitrage each have a positive correlation with the Baa rate and the correlations of the Baa rate with the other styles are negative. The pattern of APA correlations with the Baa rate to Aaa rate ratio is similar except there is a very weak negative correlation in the case of convertible arbitrage and a very weak positive correlation in the case of global macro.

To further explore the relationship between the APAs and interest rates, we regress each APA series on the Treasury bond rate the Baa rate. The results are on Table 8 and they generally confirm the earlier observations concerning how investors make allocations based upon the chosen interest rate variables. We offer the reminder that the regressions only have three degrees of freedom, however and the tstatistics and F-statistics are only descriptive.

The signs of the correlations with the Baa rate on Table 7 and of the slope coefficients on Table 8 suggest that investors tend to increase (decrease) allocations to distressed debt and convertible arbitrage when interest rates on lower grade investments increase (decrease). Investors tend to decrease (increase) or not adjust allocations to the styles long/short strategy, global macro, multi-strategy and statistical arbitrage when rates on lower grade investments increase (decrease).

The positive relationship between the APAs of the distressed debt and convertible arbitrage and the indicated interest rate variables should not be surprising given that these styles earn a return based upon the performance of lower-grade bond. These specific results are congruous with Jaeger and Wagner (2005), which uses factor analysis to explain the returns of several styles. In a regression of distressed debt returns and convertible arbitrage returns on a set of factors including the return of the CSFB High Yield Index, the coefficient on the returns of the CSFB index had a tstatistic in excess of four in each case.

Because of the interrelationship of the APAs, we should be careful about how we interpret the negative relationships on Table 7. An increase in the APA of one style would tend to decrease the APA of another style. So the negative correlations on Table 7 do not necessarily mean that investors expect the corresponding styles will have a poor performance 
when the Baa increases, but it may only mean that the expectation is that those styles will not perform as well in relative terms.

\section{CONCLUSION}

We describe the trends and time-series relationship of several variables obtained from the seven Deutsche Bank Alternative Investment Surveys (DBAIS) conducted over the period 2002-2009. The goal has been to call attention to the survey and give some insights that will lay the foundation for future research. Although the length of each time series prevents rigorous analysis, we offer these observations:

- Participation in the survey has grown dramatically, as has the amount of information it provides

- The relative participation by banks in the survey has grown and the relative participation by foundations and endowments has declined

- There has been an increase in the use of managed accounts

- With respect to the APA data, the styles distressed debt and convertible arbitrage are positively correlated with each other and with the Baa bond rate. Those styles and the Baa bond rate are negatively correlated with the APAs of the long/short strategy, global macro and multistrategy styles

- Some of the pairs of APAs have strong correlations, e.g., the positive correlation between the multi-strategy and statistical arbitrage styles and the negative correlation between the long-short and distressed debt styles

In the years ahead the DBAIS may become more standardized from year to year and the sample size of each series will increase to allow for more conclusive results. The results at this point are still valuable, however, in that they provide current insights and the motivation for future research into alternative investments.

\section{REFERENCES}

Agarwal, V., N.D. Daniel and N.Y. Naik, 2009. Role of managerial incentives and discretion in hedge fund performance. J. Finance, 64: 2221-2256. DOI: 10.1111/j.1540-6261.2009.01499.x

Brooks, R. and J.B. Gray, 2004. History of the forecasters. J. Portf. Manage., 31: 113-117. DOI: 10.3905/jpm.2004.443329

Hu, B., 2008. Hedge funds lower fees, lengthen lockups on new funds. The Financial Express. http://www.financialexpress.com/news/hedgefunds-lower-fees-lengthen-lockups-on-newfunds/394401/1

Jaeger, L. and C. Wagner, 2005. Factor modeling and benchmarking of hedge funds: Can passive investments in hedge fund strategies deliver? J. Altern. Invest., 8: 9-36. DOI: 10.3905/jai.2005.608030

Kishan, S., 2009. Hedge-fund investors remove record $\$ 152$ billion (update 1). Bloomberg News. http://www.bloomberg.com/apps/news?pid=newsar chive \&sid=aL3fOSkanqs8

Kouwe, Z., 2009. Hedge fund withdrawals keep rising. The New York Times. http://dealbook.blogs.nytimes.com/2009/04/21/hed ge-fund-withdrawals-keep-rising

Phillips, M.K., 2009. Cross roads. CFA Mag., 20: 32-34. DOI: $10.2469 / \mathrm{cfm} . v 20 . n 3.13$ 